\title{
EDITORIAL
}

\section{Ergonomics in radiology - Time to revisit}

\section{Chander Mohan, SM}

Interventional Radiology, BLK Superpsecialty Hospital, Pusa Road, New Delhi, India. E-mail: brigcmohan@gmail.com

Radiology is at the forefront of specialties which have undergone rapid technological revolution. Newer imaging techniques have come up at breathtaking pace along with their use into new applications. This has led to a tremendous increase in imaging volumes of a radiology department to be handled on daily basis. This is coupled with ever-increasing need to compare with all available previous studies for comprehensive evaluation, assessment of progression, or improvement in follow up cases.

To handle such enormous workload, there has been an increase in the demand for workforce in the radiology department as well as newer methods to improve workflow. Most radiology departments have started to drift toward being filmless and driven by picture archiving \& communication system (PACS) with the reporting rooms evolving into radiologists sitting on multiple radiological workstations side by side, resembling cyber cafes of yester years.

Although administrators pay great attention to methods that improve the workflow in the department, increasing workload on the radiologists is very much neglected. The primary reason for this neglect has been that traditionally the radiologist's job is considered to be less physically demanding. While we do not have to make clinical rounds or stand in the operation theaters for long hours, our jobs require us to sit glued in front of the workstations for long. This has led to a different set of workplace-based problems such as repetitive stress injuries (RSIs), visual problems, headaches, and musculoskeletal problems in radiologists who often under tremendous work pressure spend most of their time on the workstations. For example, Boiselle et al. reported that in their department, radiologists who spent more than 8 hours daily at workstations, $58 \%$ of them reported symptoms of RSI and 38\% were actually diagnosed with RSIs. In addition, certain subspecialists in radiology such as ultrasonologists are more susceptible to particular RSIs of shoulder, neck, elbow, and lower back pain. Similarly, intervention radiologists are prone to musculoskeletal problems due to protective gear. ${ }^{[2]}$

These issues have now started to gain attention of the medical community over the past few years. There is a pressing need for defining ergonomic guidelines for radiology department planning in India. This is not only necessary to improve the health and well-being of the radiologists but also increasing their ability to make more accurate diagnoses.

Many issues need our attention in this, which are often neglected and hardly ever discussed among the radiologists themselves. These include things such as lighting, acoustics, furniture, seating, posture, and arrangement of things at the workstation.

The most important issue is the role of lighting. As we are transitioning into a filmless world, this transition has led to variable requirements for ambient lighting for the view boxes and the workstations as the transition to filmless is partial in many setups with the view boxes still being present along with workstations in the reporting rooms. The use of fluorescent lighting leads to a higher brightness level which decreases the accommodation and visual acuity. The workstations need to be provided with individual ambient lighting comfortable to the needs of the radiologist working at that time where one radiologist who needs light to read written material does not end up causing glare to the other radiologists working in the room.

Ergonomics of the working space is also very important. It appears appropriate to have three monitors at each workstation. One of these being a low resolution to see the worklists while the other two being high resolution to review imaging. The distance of the eye from the screen is also important to minimize the eye strain. Then all the

This is an open access journal, and articles are distributed under the terms of the Creative Commons Attribution-NonCommercial-ShareAlike 4.0 License, which allows others to remix, tweak, and build upon the work non-commercially, as long as appropriate credit is given and the new creations are licensed under the identical terms.

\begin{tabular}{|l|l|}
\hline \multicolumn{2}{|c|}{ Access this article online } \\
\hline Quick Response Code: & \\
\cline { 1 - 2 } & Website: \\
\hline & www.jri.org \\
\cline { 2 - 3 } & \\
\hline
\end{tabular}

Cite this article as: Mohan C. Ergonomics in radiology - Time to revisit. Indian J Radiol Imaging 2018;28:271-2. 
workstation components such as the monitors, dictation devices, phones, and printers should be within short reach of the radiologist working at the workstation with each thing getting its designated space at the time of designing of the reporting room.

Another very important thing is acoustics. There are lots of equipments in a reporting room such as printers, keyboards, and sounds from the abutting workstations and the physicians who come over to discuss their cases. Sound-absorbent materials need to be carefully chosen to drown out the noise and implemented into the ceilings, walls, or the partitions between the workstations. Noise from human sources is always more distracting than the mechanical sources and should be minimized to the extent possible.

To limit RSIs such as carpal tunnel syndrome which affects the hand and the wrist, the placement of the keyboard and the mouse is also very important. The radiologist's work differs from the computer-bound nonradiologists work as it involves a lot of mouse motion and clicks rather than keyboard use. The keyboard and mouse should be placed at a comfortable height with plenty of desk space to allow free movements. Having flat mouse also helps in terms of minimizing wrist extension.

Better selection of furniture such as the desks and the chairs is also essential. Height-adjustable furniture if available can also help the radiologist to avoid sitting in the same position for long. Radiologists should be encouraged to try out the different designs available with the vendors at the time of planning of the reporting rooms and mutually agreed upon furniture should be procured.

Different people have different needs for their environment climate. There is a need to manage the airflow and the climate at the push of a button. Mutually agreeable temperatures can be defined and implemented.

Along with this, the radiologists also need to understand that their work now has evolved into sitting in same postures for a long time and often doing repetitive tasks which strain particular muscles and joints more than others. Along with ergonomic planning of the chairs and desks on which they operate, they should also realize the importance of taking adequate breaks during work which will improve not just their health but also their productivity. It is of paramount importance to incorporate movement into our daily routine with planned breaks every $30-45 \mathrm{~min}$ to prevent strain and discomfort. Counter-strain stretching is another practice which needs to be incorporated into our habits and involves stretching in the opposite direction of our usual sustained position of stress.

A proper ergonomic training at institute level is also essential for the radiologists to make better use of the equipments available to them. This includes things like adjusting the chair height so that the elbow height is at the level of the desk along with use of arm and footrests wherever possible. Along with this, excellent lumbar support should be maintained to prevent lower back strain. Preferably, radiologists' eyes should be at level with the upper third of monitor which will help reduce neck strain. Switching between standing and sitting positions is another excellent measure to prevent being in one position for long.

Today, three-dimensional computer-aided simulation and rendering techniques are available for more efficient designing which allow the radiologists to experience various design options at the planning stage which is a big advantage over the paper designs traditionally used. In the long run, the upfront costs of these ergonomic measures will be far outweighed by the increase in the efficiency and accuracy of the radiologists. It is high time that we pay attention to these ergonomic aspects or we the specialists who diagnose other peoples injuries may end up with stress injuries of our own!

\section{References}

1. Boiselle PM, Levine D, Horwich PJ, Barbaras L, Siegal D, Shillue K, et al. Repetitive stress symptoms in radiology: Prevalence and response to ergonomic interventions. J Am Coll Radiol 2008;5:919-23.

2. Klein LW, Miller DL, Balter S, Laskey W, Haines D, et al. Occupational health hazards in the interventional laboratory: Time for a safer environment. Radiology 2009;250:538-44. 